\begin{abstract}
Iranica
Abstracta Iranica Revue bibliographique pour le domaine irano-aryen

Volume 32-33 | 2013

Comptes rendus des publications de 2009-2010
\end{abstract}

\title{
Chuto kenkyu (Etudes du Moyen-Orient). n505, Vol. II
}

\section{Yoko Suzuki}

\section{(2) OpenEdition}

\section{Journals}

Édition électronique

URL : http://journals.openedition.org/abstractairanica/41010

DOI : 10.4000/abstractairanica.41010

ISSN : 1961-960X

Éditeur :

CNRS (UMR 7528 Mondes iraniens et indiens), Éditions de l'IFRI

\section{Édition imprimée}

Date de publication : 1 décembre 2013

ISSN : 0240-8910

\section{Référence électronique}

Yoko Suzuki, «Chuto kenkyu (Etudes du Moyen-Orient). n505, Vol. II », Abstracta Iranica [En ligne], Volume 32-33 | 2013, document 448, mis en ligne le 01 juillet 2016, consulté le 26 septembre 2020. URL : http://journals.openedition.org/abstractairanica/41010 ; DOI : https://doi.org/10.4000/ abstractairanica.41010

Ce document a été généré automatiquement le 26 septembre 2020.

Tous droits réservés 


\title{
Chuto kenkyu (Etudes du Moyen- Orient). n505, Vol. II
}

\author{
Yoko Suzuki
}

\section{RÉFÉRENCE}

Chuto kenkyu (Etudes du Moyen-Orient). Chuto chosakai, 2009/2010, no. 505, vol II, Tokyo, $144 \mathrm{p}$.

1 La Chuto chosakai (Organisation de la recherche du Moyen-Orient) est une organisation affiliée au ministère des Affaires étrangères du Japon, fondée en 1956. Elle publie depuis 1958 ladite revue aux fins de rendre compte, aux hommes d'affaires et aux chercheurs, de ce qui se passe dans cette région du monde, peu connue au Japon mais devenu de plus en plus importante dans son plan économique.

2 Une grande partie de ce numéro est consacrée à l'analyse du mouvement populaire après la dixième élection présidentielle qui a eu lieu en Iran en 2009.

3 Numéro spécial : l'avenir de l'Iran en ébullition - La X ${ }^{\text {ème }}$ élection présidentielle et l'incertitude politique

4 Masayuki Yamauchi, « 'la fin du début' du régime des juristes islamiques - Mutation de la République islamique d'Iran » (hougakusha touchi taisei no 'owari no hajimari'-Iran·islam kyouwakoku no henshitsu)

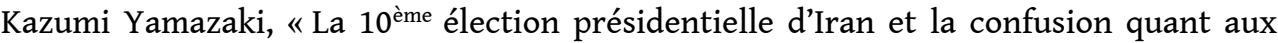
résultats » (dai 10 ki iran daitouryousenkyo to sono kekka wo meguru konran) Politique domestique :

7 Yasuyuki Matsunaga, "Transition interne du regime - les choix de Khameneyi, le leader suprême et leurs résultats" (naibu karano taiseihenkan he - hāmeneyi saikou shidousha no sentaku to sono kiketsu)

Hidenobu Sato, «quelle est l'armée des Gardiens de la révolution? (isuramu kakumei boumeitai toha nanika) 

shakai wo sasaeru wakamono no jitsuzou)

11 Ārezū Fekrejahānī, «Attente du peuple vis à vis de l'élection présidentielle et écart avec les résultats acquis - Le fond de sa contestation » (daitouryou senkyo kikanchu no kitai to kekka no gyappu - hitobito no kougi no haikei ni arumono ha)

12 Kazumi Yamazaki, «Participation des femmes dans le mouvement populaire en Iran » (iran ni okeru taishuu undou heno josei sanka)

13 Politique internationale :

14 Yoko Hirose, «Relations internationales entre l'Iran, la Russie et le Caucase » (iran to roshia, kokasasu no kokusai kankei - saikinno jirei kara)

15 Isamu Nakajima, "Soupçons sur l'arme nucléaire iranienne et réaction excessive d'Israël - deux menaces autour des problèmes nucléaires » (iran no kakugiwaku to isuraeru no kajou hannou - kakugiwaku wo meguru 2tsuno kyoui)

16 Akio Kawai, «Réactions des pays du Golfe persique aux résultats de l'élection présidentielle d'Iran » (iran daitouryou senkyo kekka ni taisuru wangan arabu shokoku no hannou)

17 Chie Ezaki, « Relations internationales entre Iran et Jordanie-Palestine - analyse de la stratégie de la Jordanie sur le Hamās » (iran to yorudan'paresuchina tono kankei - yorudan no tai hamās seisaku wo jiku to shite).

\section{AUTEURS}

YOKO SUZUKI

Paris 